\title{
Development of in vitro tooth staining model and usage of catalysts to elevate the effectiveness of tooth bleaching
}

\author{
Bor-Shiunn Lee ${ }^{a}$, Shih-Hao Huang ${ }^{a}$, Yu-Chih Chiang ${ }^{a}$, Yu-Shan Chien ${ }^{a}$, \\ Chung-Yuan Mou ${ }^{b}$, Chun-Pin Lin ${ }^{a, *}$ \\ a School of Dentistry and Graduate Institute of Clinical Dentistry, College of Medicine, National Taiwan University and National Taiwan \\ University Hospital, Taipei, Taiwan \\ b Department of Chemistry, National Taiwan University, Taipei 106, Taiwan
}

\section{A R T I C L E I N F O}

Article history:

Received 20 April 2006

Received in revised form

11 December 2006

Accepted 19 January 2007

Keywords:

Tooth bleaching

Orange II

Tooth staining

\begin{abstract}
A B S T R A C T
Objectives. Whole blood or tea was frequently used to stain the teeth for measuring the effectiveness of different bleaching materials. However, the components of blood or tea cannot be quantitatively determined and variability might exist among different brands of tea. The purpose of this study was to develop a reproducible in vitro tooth-staining model to simulate the intrinsic discoloration of teeth and evaluate the ability of two catalysts to enhance the bleaching activity of $\mathrm{H}_{2} \mathrm{O}_{2}$.

Methods. Rhodamine B, Orange II, Fe(III) phthalocyanine, and tea were used to stain the tooth specimens for 4-72 $\mathrm{h}$ and subsequently bleached by $\mathrm{H}_{2} \mathrm{O}_{2}$ for 4-72 $\mathrm{h}$. The process was photographed using a digital stereoscopic microscope and a digital camera. The image was transformed to get $L^{*}, a^{*}, b^{*}$ values of CIE Lab system with image processing software. The catalytic ability of light irradiation plus addition of Fe/Sodium-Y or Mn/Sodium-Y for specimens stained by Orange II was evaluated in test tubes and in extracted tooth model.

Results. The color of specimens stained by Rhodamine B could not be sufficiently recovered after bleaching by $\mathrm{H}_{2} \mathrm{O}_{2}$. In addition, the reaction of $\mathrm{Fe}$ (III) phthalocyanine with $\mathrm{H}_{2} \mathrm{O}_{2}$ in test tubes was too fast to be monitored. Light activation plus use of Fe/Sodium-Y or Mn/Sodium-Y could significantly accelerate the bleaching efficiency of $\mathrm{H}_{2} \mathrm{O}_{2}$.

Significance. Orange II was the most appropriate dye for tooth staining among the dyes used in this study. Addition of Fe/Sodium-Y or Mn/Sodium-Y plus light irradiation could elevate the bleaching efficacy of $\mathrm{H}_{2} \mathrm{O}_{2}$ for those specimens stained by Orange II.
\end{abstract}

(c) 2007 Academy of Dental Materials. Published by Elsevier Ltd. All rights reserved.

\section{Introduction}

The causes of tooth discoloration are usually various and multifaceted. They have been classified as extrinsic, intrinsic, and internalized discoloration [1]. Extrinsic discoloration is caused by deposition of external chromogens (i.e. metallic ions, tea, coffee, and tobacco) on the tooth surface or within the pellicle layer that adheres to enamel surface. Intrinsic discoloration occurs when the chromogens are deposited within the bulk of the tooth, usually the dentin, and caused from systemic or pulpal origin. Extrinsic stain occasionally permeates into the tooth substance through the defect of the tooth, thereby causing the intrinsic discoloration [2]. Internalized discoloration results from a number of factorssuch

\footnotetext{
* Corresponding author at: School of Dentistry and Graduate Institute of Clinical Dentistry, College of Medicine, National Taiwan University and National Taiwan University Hospital, No. 1, Chang-Te Street, Taipei 10016, Taiwan. Tel.: +886 2 23123456x7335; fax: +886 2 23821212.

E-mail address: pinlin@ha.mc.ntu.edu.tw (C.-P. Lin). 0109-5641/\$ - see front matter @ 2007 Academy of Dental Materials. Published by Elsevier Ltd. All rights reserved. doi:10.1016/j.dental.2007.01.012
} 
as developmental defects, caries, and restorative materials [1].

For most of the population, the beautiful appearance of dentition enables a person to feel confident and attractive. Therefore, numerous patients seek dental assistance for cosmetic improvement of tooth discoloration. Extrinsic stains can be corrected merely by routine prophylactic procedures, microabrasion, or macroabrasion [3]. However, improvement of intrinsic discoloration needs bleaching, laminate veneering, or even crowning in more severely discolored cases. The major disadvantages of laminate veneering or crowning are irreversible removal of tooth structure, high cost, time-consuming, and technique sensitive [4]. On the contrary, tooth bleaching is more conservative and easier to carry out, even though it has limitations in severely discolored teeth [5].

The contemporary tooth bleaching technique is based primarily on the oxidation by hydrogen peroxide or one of its precursors, and those are often used in combination with an activating agent such as heat or light [5]. The commercial products of tooth bleaching are usually fabricated in a gel form and can be administered professionally in dental clinics (in-office bleaching) or utilized by patients with trays at home (home bleaching) [6]. If researchers want to compare the efficacy of different bleaching techniques or products scientifically, study the mechanism and penetration of bleaching agents into teeth, as well as design a course for students to learn the bleaching technique, the establishment of a reliable and standard laboratory model is convenient and indispensable. Although the therapeutic effect of bleaching agents must be ultimately validated through well-controlled clinical studies, a laboratory model can provide us with preliminary results before expensive clinical trials.

During past decades, many researchers have developed laboratory models to mimic the discoloration of teeth. For example, Freccia and Peters [7] hemolyzed red blood cells by a high-speed centrifuge to obtain a hemolysate containing the hemoglobin protein, and subsequently immersed the teeth in hemolysate for numerous days. Others immersed the extracted teeth in tea, chlorhexidine, or human saliva to stain the teeth [8-10]. Testing models were utilized to investigate the etiology of chlorhexidine or quantify the whitening efficiency of bleaching products. Recently, Sulieman et al. developed a more reproducible in vitro model to stain the extracted teeth [11]. Briefly, they boiled $2 \mathrm{~g}$ of tea in $100 \mathrm{ml}$ of distilled water for $5 \mathrm{~min}$ and then immersed the samples in the tea solution for many days to create stained teeth. Although the abovementioned methods have been employed for several studies, tea or blood is still not an ideal staining source because the components cannot be quantitatively determined or ascertained. In addition, the brand of tea (Marks and Spencer's Extra Strong tea, Marks and Spencer, London, UK) [11] could not be conveniently purchased by researchers in other countries. Moreover, different brands of tea might exhibit various staining abilities to extracted teeth. These variables pose an influential bias to study the efficacy of bleaching agent. Therefore, the purpose of this study was to develop a reproducible and standard laboratory model to simulate the intrinsic discoloration of teeth, and this model can be used to assess the effect of tooth bleaching agents on discolored teeth. Moreover, enhanced bleaching activity of $\mathrm{H}_{2} \mathrm{O}_{2}$ by two catalysts was investigated.

\section{Materials and methods}

\subsection{Dye selection}

The appropriate dye was defined as, that it could be used to evaluate the bleaching activity of hydrogen peroxide in both the stained tooth and test tube. In order to find the proper dye to simulate the stain of the tooth, Rhodamine B, Orange II, $\mathrm{Fe}$ (III) phthalocyanine (Sigma-Aldrich Co., St. Louis, USA) were selected for this study, because they could meet the following requirements:

(1) The chemical formula of the selected dye could simulate the stain of the tooth. Namely, the dye should exhibit similar structures to pigmented carbon-ring compounds or carbon double-bond compounds [12].

(2) The molecular weight of the selected dye was small enough to easily penetrate into the tooth structure.

(3) The selected dye could be decomposed by $\mathrm{H}_{2} \mathrm{O}_{2}$.

The chemical structures of selected dye were shown in Fig. 1. Dyes were tested to see if they could induce tooth staining and the stained tooth could be bleached.

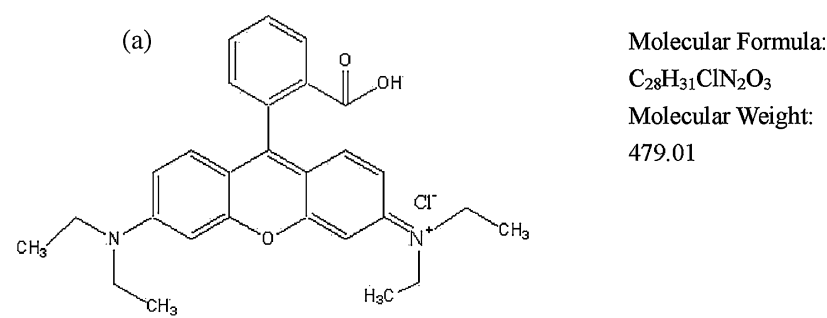

(b)<smiles>CS(=O)(=O)c1ccc(/N=N/c2c(O)ccc3ccccc23)cc1</smiles>

Molecular Formula: $\mathrm{C}_{16} \mathrm{H}_{11} \mathrm{~N}_{2} \mathrm{NaO}_{4} \mathrm{~S}$ Molecular Weight: 350.32

(c)

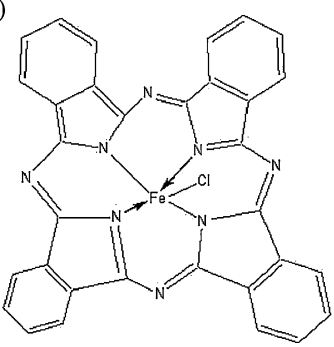

Molecular Formula: $\mathrm{C}_{32} \mathrm{H}_{16} \mathrm{ClFeN}_{8}$ Molecular Weight: 603.82

Fig. 1 - The chemical structure of (a) Rhodamine B, (b) Orange II, and (c) Fe(III) phthalocyanine. 


\subsection{Specimen preparation}

Extracted human third permanent molars were used in this study. Crowns with caries, restorations, or fractures were discarded. Any remaining soft tissues were thoroughly removed from the tooth surfaces with a dental scaler (Sonicflex 2000, KaVo Co., Biberbach, Germany) under running water. All teeth were then stored in $4^{\circ} \mathrm{C}$ distilled water containing $0.2 \%$ thymol to inhibit microbial growth until use.

While fully hydrated, the crown portions of each third molar were sectioned in half mesiodistally by means of a low-speed diamond wafering blade (Isomet; $10.2 \mathrm{~cm} \times 0.3 \mathrm{~mm}$, arbor size 0.5 in., series $15 \mathrm{HC}$ diamond; Buehler Ltd., Lake Bluff, IL) and the root portions were discarded. Each specimen was fixed by using silicon impression material (Rapid liner; Coltene/Whaledent Inc., Mahwah, NJ, USA) with the sectioned surface facing upward to keep the examined area unchanged during successive observations.

\subsection{Color evaluation}

Before the tooth stain development, the cut surface of each specimen was photographed using a digital stereoscopic microscope (Leica MZ8, Heebrugg, Switzerland) at 8-25× magnification. The images were captured by a digital camera (Olympus E-300, Olympus Imaging America Inc., New York, USA) in combination with a $50 \mathrm{~mm} \mathrm{1:2} \mathrm{macro} \mathrm{lens} \mathrm{as} \mathrm{well} \mathrm{as}$ an automatic ring-light electronic flash illumination to record the specimen color (Fig. 2). The processes of tooth stain development and bleaching were also photographed using the same apparatus. The tooth specimen was divided into three areas: enamel, outer dentin (just inside the dentinoenamel junction), and inner dentin (just lateral to the pulp chamber) [13]. Three points without light reflection were chosen in each area for color evaluation. Subsequently, the image of the tooth specimen was transformed to derive a set of numerical values in terms of the International Commission on Illumination (CIE) Lab system with image processing software (Photoshop 7.02,

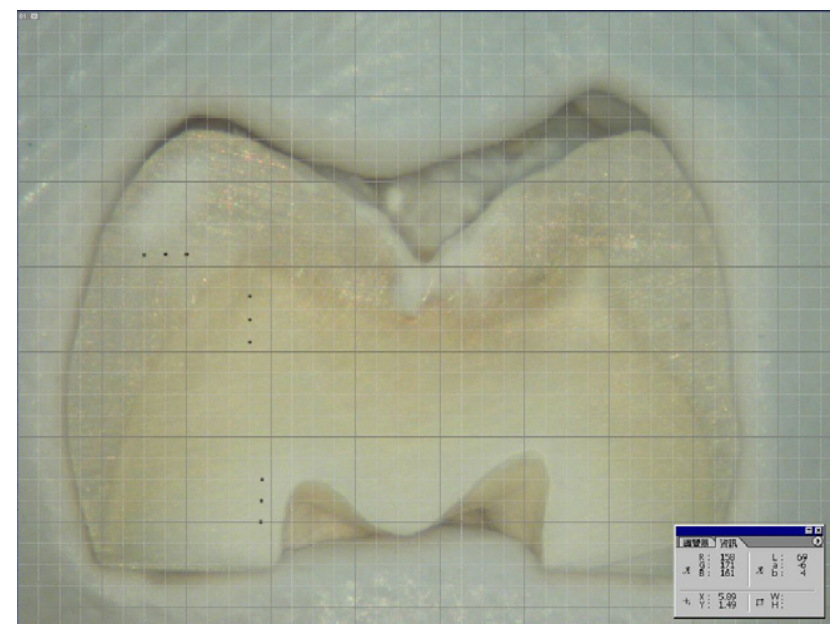

Fig. 2 - Image of tooth specimen taken from digital stereoscopic microscope and digital camera. Three points without light reflection were chosen in each of three areas (enamel, outer dentin, and inner dentin) for color evaluation.
Adobe System Inc.). The CIE Lab system is based on three separate color receptors (red, green, and blue) and allows color specification within a three dimensional space [14]. The $L^{*}$ value represents the degree of lightness within a sample and ranges from 0 (black) to 100 (white). The $a^{*}$ value detects the degree of greenness (negative $a^{*}$ ) or redness (positive $a^{*}$ ), while the $b^{*}$ value measures the degree of blueness (negative $b^{*}$ ) or yellowness (positive $b^{*}$ ) of the sample. The overall color difference in the specimens in each group $\left(\Delta E^{*}\right)$ was calculated using the following formula:

$\Delta E^{*}=\sqrt{\left(\Delta L^{*}\right)^{2}+\left(\Delta a^{*}\right)^{2}+\left(\Delta b^{*}\right)^{2}}$

In addition, the CIE Lab system was used to evaluate the color changes of all 16 tooth shade guide tabs (Vita, Zahnfabrik, Germany) at different time period of $0,1,2,3,4,5$, and 6 days as a control group to evaluate the stability of this color assessing technique. The 16 tooth shade guide tabs included A1, A2, A3, A3.5, A4, B1, B2, B3, B4, C1, C2, C3, C4, D2, D3, and D4.

\subsection{Tooth stain development and bleaching of stained tooth}

Rhodamine B and Orange II were diluted with distilled water to a concentration of $0.15 \mathrm{mM}$ solution. Fe(III) phthalocyanine was diluted with dimethyl sulfoxide (DMSO) (Sigma-Aldrich Co., St. Louis, USA) because of its insolubility in distilled water. Additionally, a control group comprising tea solution was prepared by immersing one commercial tea bag (Pure Ceylon Tea, Stassen Exports Ltd., Colombo, Sri Lanka) in $25^{\circ} \mathrm{C}$ $200 \mathrm{ml}$ distilled water for $5 \mathrm{~min}$. Twenty-four tooth specimens were randomly divided into four groups with six specimens in each group, and then immersed in $10 \mathrm{ml}$ of Rhodamine $\mathrm{B}$, Orange II, Fe(III) phthalocyanine, and tea solution, respectively. The stain process was monitored at $4,24,48,72 \mathrm{~h}$ using the above-mentioned image analysis technique. After $72 \mathrm{~h}$ of stain development, all tooth specimens were immersed in $10 \mathrm{ml}$ of $30 \% \mathrm{H}_{2} \mathrm{O}_{2}$ solution (Wako Pure Chemical Industries Ltd., Osaka, Japan) for bleaching processing. The $30 \% \mathrm{H}_{2} \mathrm{O}_{2}$ was refreshed $4,24,48$, and $72 \mathrm{~h}$ after immersion and the color of the tooth specimen was evaluated simultaneously at the same time period with the same image analysis technique.

\subsection{Enhanced bleaching efficacy of $\mathrm{H}_{2} \mathrm{O}_{2}$ with $\mathrm{Fe}^{3+}$ or $\mathrm{Mn}^{2+}$ catalysts}

$0.15 \mathrm{mM}, 10 \mathrm{ml}$ of Rhodamine B, Orange II, and Fe(III) phthalocyanine were prepared, respectively, in test tubes. Subsequently, $10 \mathrm{ml}$ of $30 \% \mathrm{H}_{2} \mathrm{O}_{2}$ was added into each tube and the intensity of absorbing peak of each dye (Rhodamine $\mathrm{B}$ : $554 \mathrm{~nm}$; Orange II: $482 \mathrm{~nm}$; Fe(III) phthalocyanine: $675 \mathrm{~nm}$ ) was measured using a spectrophotometer (U-3010, Hitachi, Tokyo, Japan) at intervals of $10 \mathrm{~min}$.

In order to fabricate the catalyst of $\mathrm{H}_{2} \mathrm{O}_{2}$, two types of metal ion catalyses, $\mathrm{Fe}^{3+}$ and $\mathrm{Mn}^{2+}$, derived from manganese(II)-nitrate tetrahydrate $\left(\mathrm{Mn}\left(\mathrm{NO}_{3}\right)_{2} \cdot 4 \mathrm{H}_{2} \mathrm{O}\right)$ and ferric nitrate nonahydrate $\left(\mathrm{Fe}\left(\mathrm{NO}_{3}\right)_{3} \cdot 9 \mathrm{H}_{2} \mathrm{O}\right)$, respectively, were prepared with distilled water to form a $10 \mathrm{mM}, 100 \mathrm{ml}$ solution. One gram of Sodium-Y zeolite (Sigma-Aldrich Co., St. Louis, USA) serving as the carrier of metal ions was added 
to the solution under stirring at $250 \mathrm{rpm}$ to form Fe/Sodium$\mathrm{Y}, \mathrm{Mn} /$ Sodium-Y catalysts, respectively. After stirring for $2 \mathrm{~h}$ at room temperature, the solution was washed with distilled water three times followed by desiccation in a $100^{\circ} \mathrm{C}$ oven $(\mathrm{DH}-$ 600, Dengyng Instruments Co. Ltd., Taipei, Taiwan) for $24 \mathrm{~h}$. Finally, the product was pulverized by a Spex 8000 alumina ball mill and kept in a dry box until use.

In this part of study, only Orange II was selected as the dye to evaluate the catalytic activity of the Fe/Sodium-Y and $\mathrm{Mn} /$ Sodium-Y because teeth stained by Rhodamine B could not be effectively bleached by $\mathrm{H}_{2} \mathrm{O}_{2}$. Moreover, the reaction of $\mathrm{Fe}$ (III) phthalocyanine with $\mathrm{H}_{2} \mathrm{O}_{2}$ in a test tube was too fast to be detected, and it was difficult to monitor the changes of absorbing intensity with time.

The catalytic activities of Fe/Sodium-Y and Mn/Sodium-Y were investigated in test tubes as well as using extracted tooth model stained by Orange II.

Six groups (Groups A to F) were included in test tubes:

- Group A: $0.15 \mathrm{mM}, 10 \mathrm{ml}$ of Orange II reacted with $10 \mathrm{ml}, 30 \%$ $\mathrm{H}_{2} \mathrm{O}_{2}$ in dark room.

- Group B: $0.15 \mathrm{mM}, 10 \mathrm{ml}$ of Orange II reacted with $10 \mathrm{ml}, 30 \%$ $\mathrm{H}_{2} \mathrm{O}_{2}$ and $0.01 \mathrm{~g} \mathrm{Fe} /$ Sodium-Y in dark room.

- Group C: $0.15 \mathrm{mM}, 10 \mathrm{ml}$ of Orange II reacted with $10 \mathrm{ml}, 30 \%$ $\mathrm{H}_{2} \mathrm{O}_{2}$ and $0.01 \mathrm{~g} \mathrm{Mn} /$ Sodium-Y in dark room.

- Group D: $0.15 \mathrm{mM}, 10 \mathrm{ml}$ of Orange II reacted with $10 \mathrm{ml}$, $30 \% \mathrm{H}_{2} \mathrm{O}_{2}$ and activated by $27 \mathrm{~W}$ of white light irradiation (FML27EX-N, Hitachi, Japan) for $15 \mathrm{~min}$.

- Group E: $0.15 \mathrm{mM}, 10 \mathrm{ml}$ of Orange II reacted with $10 \mathrm{ml}, 30 \%$ $\mathrm{H}_{2} \mathrm{O}_{2}$ and $0.01 \mathrm{~g} \mathrm{Fe} /$ Sodium-Y, and activated by $27 \mathrm{~W}$ of white light irradiation for $15 \mathrm{~min}$.

- Group F: $0.15 \mathrm{mM}, 10 \mathrm{ml}$ of Orange II reacted with $10 \mathrm{ml}$, $30 \% \mathrm{H}_{2} \mathrm{O}_{2}$ and $0.01 \mathrm{~g} \mathrm{Mn} /$ Sodium-Y, and activated by $27 \mathrm{~W}$ of white light irradiation for $15 \mathrm{~min}$.

The distance between the light source and test tubes was fixed at $10 \mathrm{~cm}$. All groups of solution were first sieved with $0.45 \mu \mathrm{m}$ filters to remove non-reacted catalyst remnants after reaction for $10,20,30,40,50$, and $60 \mathrm{~min}$. The intensity of absorbing peak of Orange II $(482 \mathrm{~nm})$ was then measured with a spectrophotometer at specified time intervals.

In the extracted tooth model, 15 human third permanent molars were used. The specimen preparation was the same as previously described. The tooth specimens were immersed in $0.15 \mathrm{mM}$ of Orange II solution for 3 days and subsequently mixed with $10 \mathrm{ml}, 30 \% \mathrm{H}_{2} \mathrm{O}_{2}, \mathrm{H}_{2} \mathrm{O}_{2}$ plus

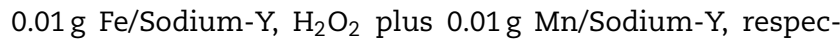
tively. Each condition contained 10 specimens and $27 \mathrm{~W}$ of white light irradiation for $15 \mathrm{~min}$ was performed during the reaction. The distance between the light source and tooth specimens was fixed at $10 \mathrm{~cm}$. The color changes in specimens after reactions for $4,24,48$, and $72 \mathrm{~h}$ were evaluated.

The significant differences of color changes among different conditions were analyzed using one-way analysis of variance (one-way ANOVA) followed by Tukey's test $(p<0.05$ was considered to represent statistical significance between tested data sets).
Table 1 - The mean (standard deviation) color changes of 16 tooth shade guide tabs at different time periods using the image analysis technique

\begin{tabular}{lrrrl} 
Day & \multicolumn{1}{c}{$\Delta L^{*}$} & $\Delta a^{*}$ & $\Delta b^{*}$ & \multicolumn{1}{c}{$\Delta E^{*}$} \\
\hline 1 & $-0.01(0.76)$ & $0.13(0.48)$ & $-0.04(0.66)$ & $0.97(0.356)$ \\
2 & $0.00(0.81)$ & $0.04(0.84)$ & $-0.18(0.57)$ & $1.14(0.48)$ \\
3 & $0.05(0.74)$ & $0.00(0.44)$ & $-0.10(0.59)$ & $0.90(0.42)$ \\
4 & $0.16(0.78)$ & $0.04(0.59)$ & $-0.26(0.40)$ & $0.96(0.41)$ \\
5 & $0.04(0.41)$ & $-0.20(0.97)$ & $-0.03(0.65)$ & $1.12(0.41)$ \\
6 & $-0.06(0.76)$ & $-0.06(0.58)$ & $0.03(0.79)$ & $1.06(0.51)$ \\
\hline
\end{tabular}

\section{Results}

\subsection{Color stability of Vita shade guide}

Table 1 demonstrates the mean color changes and standard deviation of 16 tooth shade guide tabs at different time periods of $0,1,2,3,4,5$, and 6 days using the image analysis technique. The results showed that the shade guide tabs exhibited minimal color changes at those time intervals.

\subsection{Color of tooth specimens}

The mean color of 54 tooth specimens used in this study is shown in Table 2. The $a^{*}$ values ranged from -3.81 to -4.59 while the $b^{*}$ values ranged from 13.52 to 15.83 . In addition, the $L^{*}$ value ranged from 66.50 to 76.48 . Overall, the specimens displayed an inclination toward a light green and yellow color.

\subsection{Tooth stain development and bleaching of stained tooth}

Table 3 demonstrates the mean (standard deviation) color changes after 4-72 h soaking in tea and subsequently bleached by $\mathrm{H}_{2} \mathrm{O}_{2}$ for $4-72 \mathrm{~h}$. The color changes occurred after $4 \mathrm{~h}$ in the tea solution and the absolute values of $\Delta L^{*}$ as well as $\Delta E^{*}$ increased with prolonged immersion time, indicating that the teeth had darkened. Among the examined areas, inner dentin exhibited the greatest color changes $\left(\Delta E^{*}\right)$, greater than those of enamel and outer dentin. After being bleached by $\mathrm{H}_{2} \mathrm{O}_{2}$, the color of stained specimens could be recovered close to the initial color before stain development. However, the color changes $\left(\Delta E^{*}\right)$ did not increase as the bleaching time was prolonged.

After 4-72 $\mathrm{h}$ immersion in Orange II (Table 4), the absolute values of $\Delta L^{*}$ and $\Delta E^{*}$ also increased as the immersion time was prolonged. Moreover, $\Delta a^{*}$ and $\Delta b^{*}$ values increased in dentin, representing the color of specimens moving towards the direction of red and yellow. After bleaching by $\mathrm{H}_{2} \mathrm{O}_{2}$ for

Table 2 - The mean (standard deviation) color of 54 tooth specimens using the CIE Lab system

\begin{tabular}{lccc} 
& $L^{*}$ & $a^{*}$ & $b^{*}$ \\
\hline Enamel & $66.50(6.63)$ & $-4.20(1.34)$ & $13.52(3.78)$ \\
Outer dentin & $76.08(5.01)$ & $-3.81(1.86)$ & $15.83(3.64)$ \\
Inner dentin & $76.48(6.14)$ & $-4.59(0.79)$ & $14.78(3.58)$ \\
\hline
\end{tabular}


Table 3 - Mean (standard deviation) color changes after 4-72 $\mathrm{h}$ soaking in tea (S) and subsequently bleached by $\mathrm{H}_{2} \mathrm{O}_{2}$ for 4-72 h (B)

\begin{tabular}{ccccr} 
Hours & \multicolumn{1}{c}{$\Delta \mathrm{L}^{*}$} & \multicolumn{1}{c}{$\Delta a^{*}$} & \multicolumn{1}{c}{$\Delta b^{*}$} & $\Delta \mathrm{E}^{*}$ \\
\hline Enamel & & & & \\
S4 & $-3.30(2.66)$ & $2.02(2.66)$ & $2.36(2.94)$ & $5.99(1.91)$ \\
S24 & $-5.78(2.48)$ & $1.48(1.09)$ & $3.72(2.50)$ & $7.44(2.50)$ \\
S48 & $-6.06(3.51)$ & $1.34(3.52)$ & $2.78(2.11)$ & $7.92(2.92)$ \\
S72 & $-8.06(2.05)$ & $1.08(2.60)$ & $1.76(2.62)$ & $9.00(1.76)$ \\
B4 & $-4.06(2.77)$ & $2.29(1.09)$ & $0.64(2.80)$ & $5.69(1.96)$ \\
B24 & $-1.90(2.51)$ & $0.66(1.13)$ & $-0.48(3.06)$ & $3.81(2.02)$ \\
B48 & $1.14(3.23)$ & $-0.24(1.38)$ & $-1.52(4.00)$ & $4.86(1.86)$ \\
B72 & $3.48(3.95)$ & $-0.44(1.56)$ & $-1.10(2.99)$ & $5.46(2.58)$ \\
Outer dentin & & & \\
S4 & $-2.46(2.52)$ & $0.22(2.07)$ & $0.92(2.68)$ & $4.20(2.09)$ \\
S24 & $-5.46(2.11)$ & $0.30(3.46)$ & $4.00(2.36)$ & $7.67(2.42)$ \\
S48 & $-7.54(3.44)$ & $2.00(4.04)$ & $2.84(2.30)$ & $9.36(3.19)$ \\
S72 & $-8.50(3.63)$ & $2.66(3.00)$ & $1.06(1.81)$ & $9.41(3.92)$ \\
B4 & $-3.20(1.37)$ & $0.00(2.36)$ & $0.26(1.34)$ & $3.97(1.56)$ \\
B24 & $-1.62(1.41)$ & $-1.12(2.13)$ & $-0.52(1.14)$ & $2.99(1.36)$ \\
B48 & $0.26(2.03)$ & $-0.66(2.20)$ & $-2.76(3.10)$ & $4.33(2.30)$ \\
B72 & $1.46(2.33)$ & $-1.40(1.94)$ & $-1.48(3.24)$ & $4.42(1.76)$ \\
Inner dentin & & & \\
S4 & $-2.70(2.33)$ & $-1.00(2.28)$ & $-1.85(3.85)$ & $5.36(1.69)$ \\
S24 & $-6.64(3.08)$ & $0.20(1.67)$ & $-3.22(5.78)$ & $9.10(4.12)$ \\
S48 & $-10.24(5.28)$ & $1.78(2.16)$ & $-4.23(7.23)$ & $12.52(6.55)$ \\
S72 & $-12.06(5.67)$ & $2.40(1.84)$ & $-4.83(4.09)$ & $14.70(5.33)$ \\
B4 & $-5.70(5.14)$ & $-0.48(2.16)$ & $-3.09(7.03)$ & $9.06(5.79)$ \\
B24 & $-3.70(4.46)$ & $0.54(1.36)$ & $-1.58(6.97)$ & $6.75(5.76)$ \\
B48 & $-2.46(3.97)$ & $0.06(1.40)$ & $-1.20(5.21)$ & $5.12(4.44)$ \\
B72 & $-1.70(2.91)$ & $-0.46(2.01)$ & $-1.08(4.79)$ & $4.75(3.55)$
\end{tabular}

Table 4 - Mean (standard deviation) color changes after 4-72 $\mathrm{h}$ soaking in Orange II (S) and subsequently bleached by $\mathrm{H}_{2} \mathrm{O}_{2}$ for $4-72 \mathrm{~h}$ (B)

\begin{tabular}{|c|c|c|c|c|}
\hline Hours & $\Delta L^{*}$ & $\Delta a^{*}$ & $\Delta b^{*}$ & $\Delta E^{*}$ \\
\hline \multicolumn{5}{|c|}{ Enamel } \\
\hline S4 & $-9.26(2.03)$ & $5.30(2.20)$ & 11.16 (3.19) & $15.85(1.70)$ \\
\hline $\mathrm{S} 24$ & $-10.58(1.96)$ & $10.46(1.82)$ & $12.20(2.28)$ & $19.44(1.59)$ \\
\hline S48 & $-11.60(1.66)$ & $9.36(2.12)$ & $13.56(1.07)$ & $20.26(1.76)$ \\
\hline S72 & $-13.02(1.47)$ & $10.40(1.64)$ & $11.80(1.91)$ & $20.47(2.40)$ \\
\hline B4 & $-11.22(1.58)$ & $5.98(2.85)$ & $8.46(3.26)$ & 15.79 (1.09) \\
\hline B24 & $-6.34(2.08)$ & $2.34(1.01)$ & $3.86(1.70)$ & $7.92(2.37)$ \\
\hline B48 & $-4.26(2.31)$ & $1.06(1.01)$ & $3.00(1.78)$ & $5.44(2.67)$ \\
\hline B72 & $-1.96(2.27)$ & $0.40(1.41)$ & $-0.06(1.90)$ & $2.90(2.29)$ \\
\hline \multicolumn{5}{|c|}{ Outer dentin } \\
\hline S4 & $-5.68(3.00)$ & $7.26(3.05)$ & 11.06 (3.06) & $14.85(3.32)$ \\
\hline $\mathrm{S} 24$ & $-7.28(1.46)$ & $11.76(2.70)$ & $15.26(4.81)$ & $20.77(4.88)$ \\
\hline $\mathrm{S} 48$ & $-9.02(1.38)$ & $13.74(1.77)$ & $17.94(3.57)$ & $24.39(3.73)$ \\
\hline S72 & $-11.54(1.38)$ & $14.08(1.80)$ & 18.34 (3.99) & $25.99(3.42)$ \\
\hline B4 & $-5.10(2.79)$ & $7.40(2.86)$ & $9.62(4.86)$ & $14.14(2.50)$ \\
\hline B24 & $-2.28(2.37)$ & $1.82(1.45)$ & $4.66(1.34)$ & $5.91(1.91)$ \\
\hline B48 & $-1.56(2.93)$ & $1.94(1.44)$ & $3.02(2.05)$ & $4.61(2.73)$ \\
\hline B72 & $-0.82(2.36)$ & $1.42(1.32)$ & $2.28(3.01)$ & $3.72(2.99)$ \\
\hline \multicolumn{5}{|c|}{ Inner dentin } \\
\hline S4 & $-8.74(1.99)$ & $10.14(1.16)$ & 16.52 (5.09) & $21.40(4.89)$ \\
\hline $\mathrm{S} 24$ & $-12.56(1.28)$ & $17.54(2.83)$ & $24.60(4.08)$ & $32.81(4.31)$ \\
\hline S48 & $-13.88(1.98)$ & $18.40(0.58)$ & $26.86(3.48)$ & $35.46(3.17)$ \\
\hline S72 & $-15.44(1.48)$ & $21.02(1.42)$ & $27.66(4.85)$ & $38.08(4.65)$ \\
\hline B4 & $-7.56(0.62)$ & $7.68(4.25)$ & 11.06 (2.99) & $15.76(3.89)$ \\
\hline B24 & $-4.22(1.60)$ & $3.06(1.66)$ & $4.82(2.00)$ & $7.49(1.51)$ \\
\hline B48 & $-2.64(2.11)$ & $2.66(0.78)$ & $2.92(3.72)$ & $5.34(3.38)$ \\
\hline B72 & $-2.48(1.73)$ & $1.78(1.63)$ & $3.08(2.44)$ & $5.02(1.90)$ \\
\hline
\end{tabular}

Table 5 - Mean (standard deviation) color changes after 4-72 $\mathrm{h}$ soaking in Rhodamine B (S) and subsequently bleached by $\mathrm{H}_{2} \mathrm{O}_{2}$ for 4-72 h (B)

\begin{tabular}{|c|c|c|c|c|}
\hline Hours & $\Delta L^{*}$ & $\Delta a^{*}$ & $\Delta b^{*}$ & $\Delta E^{*}$ \\
\hline \multicolumn{5}{|c|}{ Enamel } \\
\hline S4 & $-15.92(2.50)$ & $25.96(2.13)$ & $-12.92(2.75)$ & $33.17(3.30)$ \\
\hline $\mathrm{S} 24$ & $-19.88(1.62)$ & 27.64 (1.89) & $-15.68(1.78)$ & $37.56(1.52)$ \\
\hline S48 & $-22.12(2.84)$ & $27.52(5.37)$ & $-14.48(1.64)$ & $38.36(4.54)$ \\
\hline S72 & $-22.88(2.25)$ & $28.78(4.00)$ & $-15.20(1.66)$ & $39.89(3.60)$ \\
\hline B4 & $-16.66(2.18)$ & $24.18(5.96)$ & $-11.16(2.80)$ & $31.63(5.56)$ \\
\hline B24 & $-14.76(1.74)$ & $23.56(5.83)$ & $-13.52(3.14)$ & 31.09 (5.80) \\
\hline B48 & $-9.60(2.85)$ & $17.10(4.77)$ & $-11.08(3.57)$ & $22.59(6.29)$ \\
\hline B72 & $-5.88(2.14)$ & $16.92(2.96)$ & $-10.80(2.96)$ & $20.90(4.39)$ \\
\hline \multicolumn{5}{|c|}{ Outer dentin } \\
\hline S4 & $-14.88(3.04)$ & $28.80(7.87)$ & $-16.48(3.09)$ & $36.44(8.60)$ \\
\hline S24 & $-20.14(3.81)$ & $35.02(7.02)$ & $-20.52(2.29)$ & $45.45(7.28)$ \\
\hline $\mathrm{S} 48$ & $-21.86(4.65)$ & $35.66(8.23)$ & $-22.40(2.52)$ & 47.59 (8.87) \\
\hline S72 & $-23.36(4.69)$ & $40.70(6.68)$ & $-21.92(2.08)$ & $51.93(7.32)$ \\
\hline B4 & $-17.64(4.01)$ & $33.14(6.82)$ & $-20.84(2.22)$ & $43.03(7.58)$ \\
\hline B24 & $-13.36(1.59)$ & $28.54(4.87)$ & $-19.12(2.98)$ & $36.90(5.58)$ \\
\hline B48 & $-11.92(2.27)$ & $26.94(3.54)$ & $-16.92(2.24)$ & $34.01(4.43)$ \\
\hline B72 & $-10.02(1.78)$ & $24.42(3.40)$ & $-16.34(1.74)$ & 31.13 (3.33) \\
\hline \multicolumn{5}{|c|}{ Inner dentin } \\
\hline S4 & $-19.46(7.00)$ & $43.58(9.10)$ & $-22.58(2.63)$ & $53.00(10.57)$ \\
\hline $\mathrm{S} 24$ & $-24.72(5.45)$ & $46.18(7.26)$ & $-22.72(3.23)$ & 57.19 (8.89) \\
\hline S48 & $-26.52(6.41)$ & 44.98 (7.11) & $-21.84(0.63)$ & $56.75(8.42)$ \\
\hline S72 & $-25.98(6.55)$ & $45.30(7.55)$ & $-21.60(1.36)$ & $56.63(9.23)$ \\
\hline B4 & $-19.08(5.63)$ & $39.06(8.81)$ & $-19.52(1.46)$ & $47.78(9.80)$ \\
\hline B24 & $-15.66(1.65)$ & $35.20(5.15)$ & $-20.40(4.01)$ & $43.78(5.03)$ \\
\hline B48 & $-12.82(2.34)$ & $25.44(6.08)$ & $-15.06(2.32)$ & $32.50(5.05)$ \\
\hline B72 & $-10.28(2.98)$ & $21.40(2.02)$ & $-12.86(1.67)$ & $27.20(1.52)$ \\
\hline
\end{tabular}

$72 \mathrm{~h}$, the color of stained specimens recovered close to the initial color before stain development.

Table 5 shows the mean color changes after 4-72 $\mathrm{h}$ immersion in Rhodamine $B$. The absolute values of $\Delta L^{*}$ increased as the immersion time was prolonged. In addition, the specimen displayed red color as the $\Delta a^{*}$ values increased in outer dentin. Moreover, the color of stained specimens slightly recovered after bleaching by $\mathrm{H}_{2} \mathrm{O}_{2}$ for $72 \mathrm{~h}$.

The mean color changes stained by Fe(III) phthalocyanine are shown in Table 6 . The teeth darkened because the absolute values of $\Delta L^{*}$ increased as the immersion time was prolonged. Furthermore, increase of $\Delta a^{*}$ absolute values in enamel and $\Delta b^{*}$ absolute values in inner dentin revealed that the color of stained specimens moved toward the green and blue direction. The color of stained specimens could be effectively recovered after bleaching by $\mathrm{H}_{2} \mathrm{O}_{2}$ for $72 \mathrm{~h}$.

All color images of specimens during stain development and bleaching process were also taken by stereoscopic microscope and are shown in Fig. 3.

\subsection{Degradation of Rhodamine B, Orange II, and $\mathrm{Fe}$ (III) phthalocyanine by $\mathrm{H}_{2} \mathrm{O}_{2}$}

Fig. 4 shows the degradation of Rhodamine B, Orange II, and $\mathrm{Fe}(\mathrm{III})$ phthalocyanine by $\mathrm{H}_{2} \mathrm{O}_{2}$ in the test tube. The reaction of $\mathrm{Fe}$ (III) phthalocyanine with $\mathrm{H}_{2} \mathrm{O}_{2}$ was extremely fast. It took only $0.182 \mathrm{~s}$ for about $94 \%$ of $\mathrm{Fe}(\mathrm{III})$ phthalocyanine to be degraded. The absorbing intensity of Rhodamine B and Orange II decreased with time after adding $\mathrm{H}_{2} \mathrm{O}_{2}$. About $99 \%$ and $97 \%$ 
Table 6 - Mean (standard deviation) color changes after 4-72 $\mathrm{h}$ soaking in Fe(III) phthalocyanine (S) and subsequently bleached by $\mathrm{H}_{2} \mathrm{O}_{2}$ for 4-72 $\mathrm{h}$ (B)

\begin{tabular}{lcccr} 
Hours & \multicolumn{1}{c}{$\Delta L^{*}$} & $\Delta a^{*}$ & $\Delta b^{*}$ & $\Delta E^{*}$ \\
\hline Enamel & & & & \\
S4 & $-2.34(0.52)$ & $-1.66(1.25)$ & $-3.60(2.55)$ & $5.14(1.32)$ \\
S24 & $-5.82(1.08)$ & $-3.04(2.23)$ & $-2.52(1.00)$ & $7.38(0.98)$ \\
S48 & $-9.68(3.54)$ & $-3.46(2.03)$ & $-5.06(2.25)$ & $11.78(3.52)$ \\
S72 & $-16.46(6.73)$ & $-3.62(1.59)$ & $-8.18(4.17)$ & $19.10(6.92)$ \\
B4 & $-13.20(7.42)$ & $-3.26(1.32)$ & $-6.78(4.27)$ & $15.54(7.86)$ \\
B24 & $-6.94(3.04)$ & $-2.58(2.07)$ & $-4.64(3.42)$ & $9.19(3.88)$ \\
B48 & $-1.80(2.74)$ & $-1.50(1.53)$ & $-1.58(3.23)$ & $4.44(2.37)$ \\
B72 & $0.04(2.59)$ & $-0.96(2.05)$ & $-1.46(1.45)$ & $3.34(1.70)$ \\
Outer dentin & & & \\
S4 & $-6.52(0.54)$ & $-1.74(0.83)$ & $0.26(2.10)$ & $7.04(0.72)$ \\
S24 & $-14.32(3.08)$ & $-3.88(2.34)$ & $-0.20(1.92)$ & $15.09(3.03)$ \\
S48 & $-19.98(3.08)$ & $-2.46(2.36)$ & $-4.62(1.90)$ & $20.80(3.34)$ \\
S72 & $-27.30(5.29)$ & $-3.16(3.33)$ & $-3.80(5.85)$ & $28.29(5.93)$ \\
B4 & $-15.26(4.45)$ & $-2.74(1.06)$ & $-6.06(4.78)$ & $17.11(4.90)$ \\
B24 & $-6.50(3.55)$ & $-1.64(1.19)$ & $-3.22(3.67)$ & $8.37(2.99)$ \\
B48 & $-1.66(3.22)$ & $-0.92(2.41)$ & $0.52(4.23)$ & $4.81(3.16)$ \\
B72 & $-0.36(2.34)$ & $-0.40(1.54)$ & $-1.40(1.67)$ & $2.85(1.82)$ \\
Inner dentin & & & & \\
S4 & $-8.04(3.62)$ & $-3.36(1.93)$ & $-0.18(1.83)$ & $8.97(3.83)$ \\
S24 & $-21.52(4.12)$ & $-5.00(1.37)$ & $-2.20(2.63)$ & $22.36(4.15)$ \\
S48 & $-23.98(4.34)$ & $-5.00(3.21)$ & $-3.26(1.02)$ & $24.87(4.48)$ \\
S72 & $-29.68(6.28)$ & $-4.08(3.34)$ & $-6.86(3.37)$ & $30.97(6.63)$ \\
B4 & $-18.06(4.80)$ & $-4.20(1.50)$ & $-4.98(1.95)$ & $19.34(4.71)$ \\
B24 & $-7.86(2.03)$ & $-1.54(0.55)$ & $-3.14(1.01)$ & $8.69(1.89)$ \\
B48 & $-2.12(1.97)$ & $-1.80(1.45)$ & $-0.52(0.97)$ & $3.32(1.78)$ \\
B72 & $0.14(1.67)$ & $-0.68(2.12)$ & $0.80(2.44)$ & $3.13(1.54)$ \\
\hline
\end{tabular}

of Orange II and Rhodamine B left after reaction with $\mathrm{H}_{2} \mathrm{O}_{2}$ for $60 \mathrm{~min}$, respectively.

\subsection{Bleaching efficacy of $\mathrm{H}_{2} \mathrm{O}_{2}$ with $\mathrm{Fe}^{3+}$ or $\mathrm{Mn}^{2+}$ catalysts}

In the dark room, the absorbing intensity of Orange II in a test tube decreased as the reaction time was extended (Fig. 5). The addition of Fe/Sodium-Y or Mn/Sodium-Y could accelerate the degradation rate of Orange II and the Fe/Sodium-Y exhibited greater enhancement of bleaching ability compared with Mn/Sodium-Y. Moreover, $27 \mathrm{~W}$ of white light irradiation for $15 \mathrm{~min}$ enabled the degradation of Orange II at a greater speed compared with the groups conducted in the dark room.

In the extracted tooth model, there existed no statistically significant color changes among any groups in the inner dentin region (Fig. 6(c)). However, light activation plus addition of Fe/Sodium-Y or Mn/Sodium-Y could prominently accelerate the degradation rate of Orange II in the enamel and outer dentin regions compared with the use of $\mathrm{H}_{2} \mathrm{O}_{2}$ alone (Fig. 6(a) and (b)). No significant difference could be found between the groups using Fe/Sodium-Y or Mn/Sodium-Y.

\section{Discussion}

Blood, tea, and chlorhexidine have been the materials used to simulate the discoloration of teeth [7-10]. However, the disadvantages of these materials included that the stain components of these materials could not be quantitatively

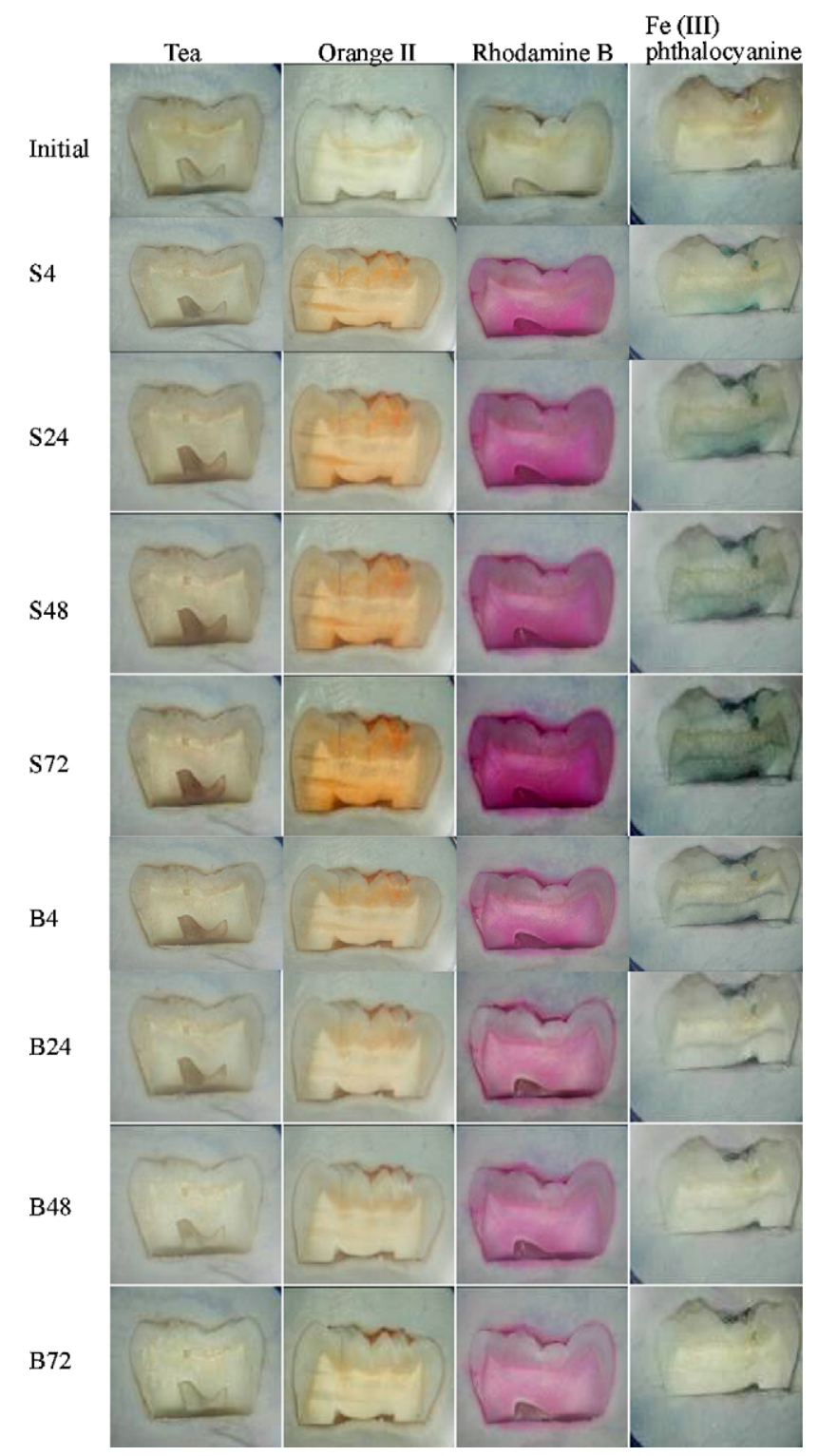

Fig. 3 - Color changes of specimens taken by stereoscopic microscope after 4-72 $\mathrm{h}$ soaking in dye (S) and subsequently bleached by $\mathrm{H}_{2} \mathrm{O}_{2}$ for $4-72 \mathrm{~h}$ (B).

determined and the stain development processes take several days. Therefore, three types of dyes (Rhodamine B, Orange II and $\mathrm{Fe}(\mathrm{III})$ phthalocyanine) were tested to stain the specimens and evaluate the bleaching ability of $\mathrm{H}_{2} \mathrm{O}_{2}$.

The tooth color was mainly determined by the color of enamel and dentin. In order to separately differentiate the color changes of enamel and dentin, the crown portions of third molars were sectioned mesiodistally and three areas selected (enamel, outer dentin, inner dentin) to individually evaluate the color changes during stain development and bleaching process [13].

Tooth color can be assessed by means of visual subjective judgment with shade guides or objective measurement using colorimeters, spectrophotometers, and image analysis techniques. Subjective color judgment with shade guides is the most frequently used method in clinical dentistry [15] because 


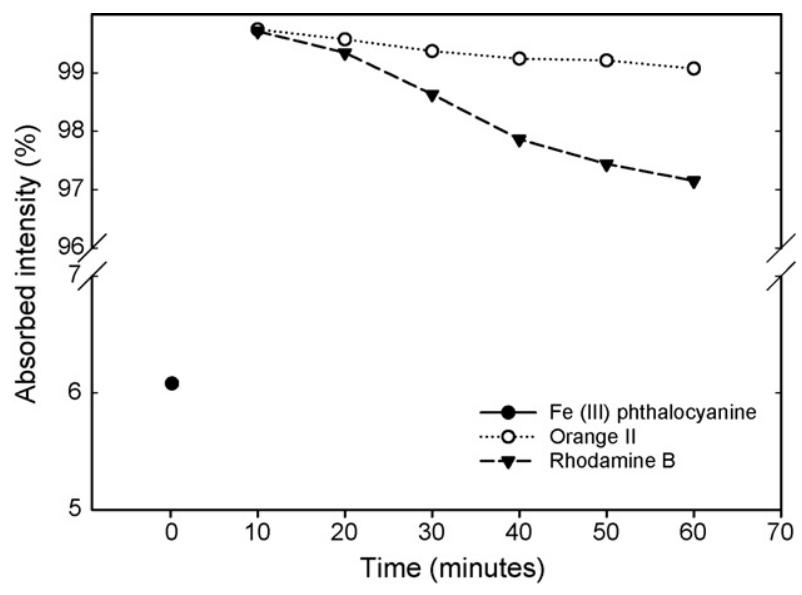

Fig. 4 - Degradation of Rhodamine B, Orange II and Fe(III) phthalocyanine with time, by hydrogen peroxide.

the human eye exhibits the ability to discriminate subtle differences in the color of objects [16]. Some variables, such as light source, metamerism, experience, age, fatigue and color blindness of human eyes, must be stringently controlled to obtain consistent results [1]. Nevertheless, numerous disadvantages are frequently described regarding this method. For example, the color perception is very subjective and often leads to individual variation. Various color evaluations might be obtained at different times even with the same operator. In addition, the shade guides are not systematic [17] and do not encompass overall color space of tooth color [18]. Furthermore, the systems of any commercial shade guides are different.

The colorimeter is one of the instrument types used to measure color difference in teeth [19]. Although it exhibits good repeatability of tooth color measurements either in vitro or in vivo [20], some drawbacks have been described. Firstly, the colorimeter is designed to measure flat surfaces of objects and it is not suitable for measurement of tooth color as the tooth surfaces are not usually flat [14]. Sec-

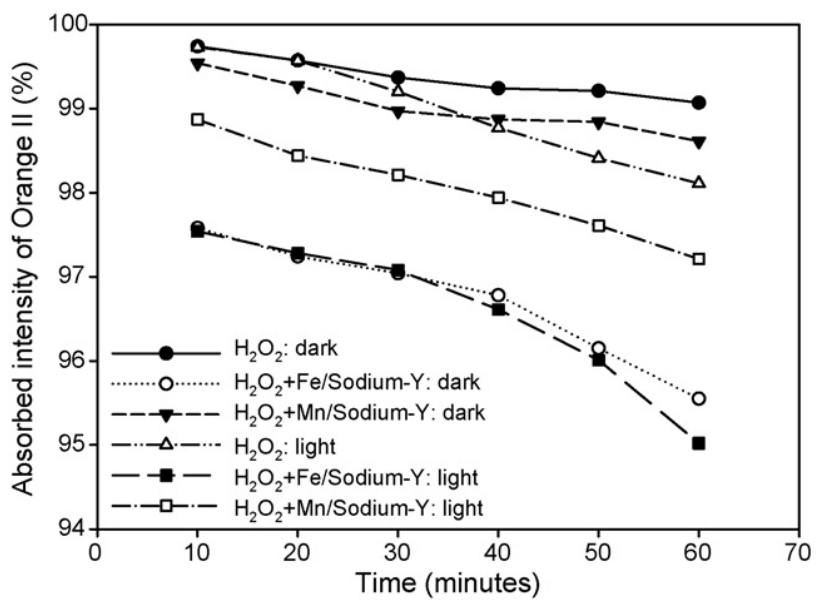

Fig. 5 - Degradation of Orange II solution in test tube by adding $\mathrm{H}_{2} \mathrm{O}_{2}, \mathrm{H}_{2} \mathrm{O}_{2}$ and $\mathrm{Mn}$ /Sodium-Y, as well as $\mathrm{H}_{2} \mathrm{O}_{2}$ and Fe/Sodium-Y. The reaction condition was subdivided into two groups including in dark room and with light activation.
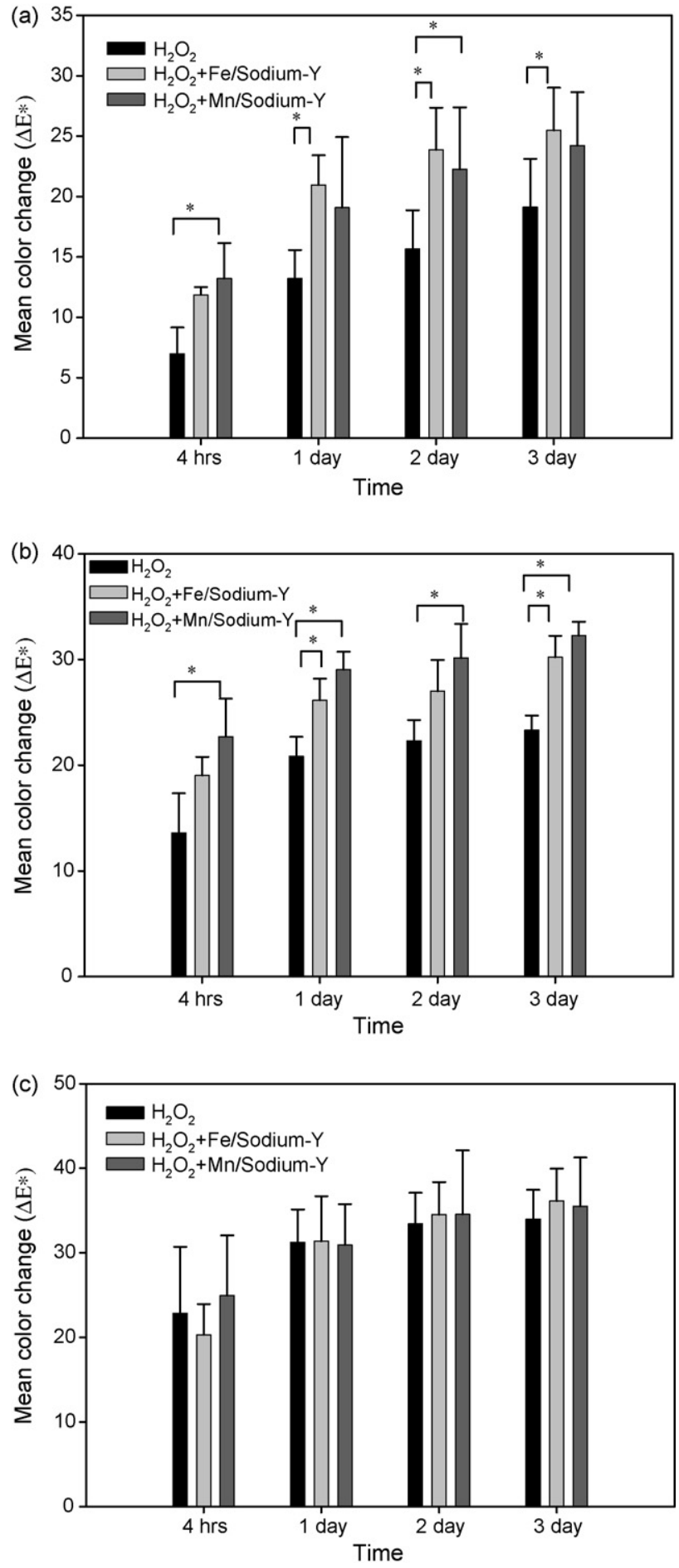

Fig. 6 - Mean color changes $\left(\Delta E^{*}\right)$ of stained tooth bleached by $\mathrm{H}_{2} \mathrm{O}_{2}, \mathrm{H}_{2} \mathrm{O}_{2}$ and $\mathrm{Mn} /$ Sodium-Y, $\mathrm{H}_{2} \mathrm{O}_{2}$ and Fe/Sodium-Y, respectively, for 4-72 h. Addition of Fe/Sodium-Y or Mn/Sodium-Y could prominently accelerate the degradation rate of Orange II in the enamel and outer dentin regions compared with the use of $\mathrm{H}_{2} \mathrm{O}_{2}$ alone. The significant difference between any two groups was labeled as "'? (a) Enamel, (b) outer dentin, and (c) inner dentin. 
ondly, inter-instrument repeatability is comparatively poor to intra-instrument repeatability [20]. Thirdly, colors assessed by colorimeter and shade guides are inconsistent [19,21]. Lastly, excessive sensitivity of the colorimeter results in variables even when the measuring distance to an individual tooth is only $1 \mathrm{~mm}$ in difference [22].

Another apparatus used to measure human tooth color is spectrophotometer. It demonstrates high accuracy and reproducibility similar to the colorimeter [23] and performs even better than shade guide assessment [16]. The major disadvantage is that the spectrophotometer is relatively expensive.

An ideal method for tooth color measurement should be reliable and inexpensive. With continuing development of computer technology, image analysis through computer operation offers another approach for objective and reproducible tooth color quantification [24]. In this study, a digital camera was used to photograph the tooth specimens and the images were subsequently transformed to obtain a set of numerical values $\left(L^{*}, a^{*}, b^{*}\right)$ with Photoshop software. Compared with the Munsell system using hue, value, and chroma [25], the CIE Lab system provides more detail to distinguish minor color differences. To test the reliability of the image analysis technique, the color changes of 16 tooth shade guide tabs at time intervals of $0,1,2,3,4,5$, and 6 days were measured. The results revealed that the color changes of shade guide tabs at different time periods were minimal, indicating the technique used in this study could provide reliable measurements (Table 1).

In comparison with the results of previous studies measuring human tooth color, the mean color values of specimens used in this study were basically similar to previous measurement (Table 2). Rubiño et al. used a colorimeter to measure the natural tooth color of 600 patients aged between 15 and 50 years old [26] and the mean values (typical deviation) of $L^{*}, a^{*}$, $b^{*}$ were 67.6 (7.0), 4.3 (2.1), 12.1 (3.3), respectively. Another study conducted by Hasegawa et al. [27] who employed spectrocolorimeter color to measure natural tooth color of 87 Japanese people aged between 13 and 84 years old demonstrated that the mean values (typical deviation) of $L^{*}, a^{*}, b^{*}$ were $73.0(5.0)$, 3.5 (1.5), 16.5 (5.0), respectively. The $L^{*}$ and $b^{*}$ values of tooth specimens used in this study were similar to the results of previous studies, however, the current specimens displayed more green color because the $a^{*}$ value was comparatively lower.

After $4 \mathrm{~h}$ of soaking in tea, Orange II, Rhodamine B, and Fe(III) phthalocyanine, respectively, the specimens began to be stained by these chromogens (Tables 3-6). The increase in $E^{*}$ values as the immersion time was prolonged indicated that the teeth were lightly stained in the beginning toward heavily stained after $72 \mathrm{~h}$ of immersion. In addition, inner dentin generally exhibited the greatest color change $\left(\Delta E^{*}\right)$ among the examined areas followed by outer dentin and enamel. The reason was suspected to be that dentin exhibits a more porous structure than enamel. These chromogens could diffuse rapidly through dentinal tubules and possibly intertubular dentin [28]. Moreover, tubule density for dentin near the dentin-enamel interface was approximately 1500-1900 tubules $/ \mathrm{mm}^{2}$, and the tubules were about $0.8 \mathrm{~mm}$ in diameter; dentin near the pulp contained 4500 tubules $/ \mathrm{mm}^{2}$ with tubule diameters at about $2.5 \mathrm{~mm}$ [29].

After bleaching by $\mathrm{H}_{2} \mathrm{O}_{2}$ for 4-72 $\mathrm{h}$, most of the specimens could recover to their original color except the group with
Rhodamine B (Fig. 3). In the specimens stained by Orange II or $\mathrm{Fe}^{3+}$ phthalocyanine, the values of $\Delta \mathrm{L}^{*}, \Delta a^{*}, \Delta b^{*}$ gradually approached to zero as the bleaching time was extended, representing most of the Orange II or $\mathrm{Fe}^{3+}$ phthalocyanine, which could be degraded by reaction with $\mathrm{H}_{2} \mathrm{O}_{2}$ for $72 \mathrm{~h}$. The bleaching ability of $\mathrm{H}_{2} \mathrm{O}_{2}$ is based on the generation of free radicals $\left.\left(\mathrm{HO}_{2}{ }^{\bullet}, \mathrm{HO}\right)^{\bullet}\right)$ derived from $\mathrm{H}_{2} \mathrm{O}_{2}$. These free radicals can attack the chromogens, causing the decomposition of chromogens. The chemical reactions are listed as the following [30]:

$$
\begin{aligned}
& \mathrm{H}_{2} \mathrm{O}_{2} \rightarrow \mathrm{H}^{+}+\mathrm{HO}_{2}^{-} \\
& \mathrm{H}_{2} \mathrm{O}_{2}+\mathrm{HO}_{2}^{-} \rightarrow \mathrm{HO}_{2}^{\bullet}+\mathrm{HO}^{\bullet}+\mathrm{OH}^{-} \\
& \mathrm{H}_{2} \mathrm{O}_{2}+\mathrm{HO}^{\bullet} \rightarrow \mathrm{HO}_{2}^{\bullet}+\mathrm{H}_{2} \mathrm{O}
\end{aligned}
$$

The degradation of Rhodamine $\mathrm{B}$, Orange II, and Fe(III) phthalocyanine by $\mathrm{H}_{2} \mathrm{O}_{2}$ was conducted in test tubes (Fig. 4). Because there existed positive correlations between the concentration and the absorbing peak of selected dyes used in this study, the concentration of a particular dye could be estimated by detecting the absorbing peak with a Spectrophotometer. After adding $\mathrm{H}_{2} \mathrm{O}_{2}$ into the test tubes, the concentrations of Rhodamine $\mathrm{B}$ and Orange II were progressively reduced with time. However, about $94 \%$ of $\mathrm{Fe}(\mathrm{III})$ phthalocyanine was degraded in only $0.182 \mathrm{~s}$. The reaction of Fe(III) phthalocyanine was too fast to be monitored by measuring the changes of absorbing intensity of $\mathrm{Fe}^{3+}$ phthalocyanine. The mechanism suspected was that Fe(III) ions inside the structure of $\mathrm{Fe}(\mathrm{III})$ phthalocyanine could play a role as a catalyst to accelerate the degradation of phthalocyanine. For Rhodamine B and Orange II, both chromogens have also been reported to be degraded by $\mathrm{H}_{2} \mathrm{O}_{2}$ [31,32]. The reaction formula of Orange II with $\mathrm{H}_{2} \mathrm{O}_{2}$ was supposed to be the following [32]:

$$
\begin{aligned}
& \mathrm{C}_{16} \mathrm{H}_{11} \mathrm{~N}_{2} \mathrm{NaO}_{4} \mathrm{~S}+(37 / 2) \mathrm{O}_{2}+(9 / 2) \mathrm{H}_{2} \mathrm{O}_{2} \\
& \rightarrow 16 \mathrm{CO}_{2}+8 \mathrm{H}_{2} \mathrm{O}+2 \mathrm{NO}_{3}{ }^{-}+\mathrm{NaHSO}_{4}{ }^{-}+3 \mathrm{H}^{+}
\end{aligned}
$$

As the specimens stained by Rhodamine B could not be effectively bleached by $\mathrm{H}_{2} \mathrm{O}_{2}$ (Fig. 3) and the reaction of $\mathrm{Fe}$ (III) phthalocyanine with $\mathrm{H}_{2} \mathrm{O}_{2}$ was too fast to be measured (Fig. 4), Orange II was the most appropriate indicator and was thus selected to test the increased bleaching ability of $\mathrm{H}_{2} \mathrm{O}_{2}$ by catalysts.

Fenton was the first scientist to discover that several metals have a special oxygen transfer property to improve the use of $\mathrm{H}_{2} \mathrm{O}_{2}$. Actually, some metals have a strong catalytic power to generate highly reactive hydroxyl radicals. Since his discovery, $\mathrm{H}_{2} \mathrm{O}_{2}$ catalyzed by iron has been called Fenton's reaction [33]. The following are the chemical reactions [34]:

$$
\begin{aligned}
& \mathrm{Fe}^{2+}+\mathrm{H}_{2} \mathrm{O}_{2} \rightarrow \mathrm{Fe}^{3+}+\mathrm{OH}^{-}+\cdot \mathrm{OH} \\
& \mathrm{Fe}^{2+}+\cdot \mathrm{OH} \rightarrow \mathrm{Fe}^{3+}+\mathrm{OH} \\
& 2 \mathrm{Fe}^{2+}+\mathrm{H}_{2} \mathrm{O}_{2} \rightarrow 2 \mathrm{Fe}^{3+}+2 \mathrm{OH}^{-}
\end{aligned}
$$


$\mathrm{H}_{2} \mathrm{O}_{2}+\mathrm{HO}^{\bullet} \rightarrow \mathrm{HO}_{2}^{\bullet}+\mathrm{H}_{2} \mathrm{O}$

$\mathrm{Fe}^{3+}+\cdot \mathrm{HO}_{2} \rightarrow \mathrm{Fe}^{2+}+\mathrm{H}^{+}+\mathrm{O}_{2}$

From the above chemical reactions, $\mathrm{Fe}^{2+}$ can react with $\mathrm{H}_{2} \mathrm{O}_{2}$ to produce $\mathrm{Fe}^{3+}$ and hydroxyl radicals $\left({ }^{\circ} \mathrm{OH}\right)(5)$, which are a powerful oxidant that can subsequently react rapidly with aromatic compounds. Hydroxyl radicals can further react with $\mathrm{H}_{2} \mathrm{O}_{2}$ to generate perhydroxyl radicals $\left(\mathrm{HO}_{2}{ }^{\bullet}\right)$ (3). Perhydroxyl radicals consequently react with $\mathrm{Fe}^{3+}$ to create $\mathrm{Fe}^{2+}$ (8). This series of reactions occurs cyclically until depletion of $\mathrm{H}_{2} \mathrm{O}_{2}$.

Fenton's reaction is an easy and simple way to catalyze $\mathrm{H}_{2} \mathrm{O}_{2}$ among many methods [33]. In the authors' pilot study, $\mathrm{Fe}, \mathrm{Mn}, \mathrm{Cu}, \mathrm{V}$ were used as the transition metals to catalyze the reaction of $\mathrm{H}_{2} \mathrm{O}_{2}$. However, $\mathrm{Cu}$ and $\mathrm{V}$ interfered with the absorbing intensity of Orange II after reacting with $\mathrm{H}_{2} \mathrm{O}_{2}$. In addition, if pure metal ions $\left(\mathrm{Fe}^{2+}\right.$ and $\left.\mathrm{Mn}^{2+}\right)$ were used to accelerate the reaction of $\mathrm{H}_{2} \mathrm{O}_{2}$, non-reacted residual metal ions were not easy to be removed and would also hamper the absorbing intensity of Orange II. Therefore, Sodium-Y carrier was used to form Fe/Sodium-Y and Mn/Sodium-Y as catalysts of $\mathrm{H}_{2} \mathrm{O}_{2}$.

The catalytic activities of Fe/Sodium-Y and Mn/Sodium$Y$ were investigated in test tubes as well as the extracted tooth model. In the test tube experiment, the addition of Fe/Sodium-Y and Mn/Sodium-Y could prominently accelerate the degradation rate of Orange II compared with the use of $\mathrm{H}_{2} \mathrm{O}_{2}$ alone (Fig. 5). Moreover, light activation could also elevate the degradation rate of Orange II compared with the tests conducted in a dark room (Fig. 5). The reason might be that the formation of $\bullet \mathrm{OH}$ under light irradiation increased [35]. It was also found that the catalytic ability of Fe/Sodium-Y was better than that of $\mathrm{Mn} /$ Sodium-Y.

In the extracted tooth model using Orange II as the chromogen, light irradiation plus the addition of Fe/Sodium-Y or $\mathrm{Mn} /$ Sodium-Y prominently accelerated the degradation rate of Orange II at any time interval, in the enamel and outer dentin regions compared with the use of $\mathrm{H}_{2} \mathrm{O}_{2}$ alone (Fig. 6(a) and (b)). However, the effects of light activation and catalysts could not be discriminated in the inner dentin (Fig. 6(c)). Moreover, no significant difference in color changes $\left(\Delta E^{*}\right)$ were found between the groups using Fe/Sodium-Y or Mn/Sodium-Y. The reason suspected was that the chromogens exhibited a higher affinity to teeth than to test tubes.

From the results of this study, Orange II was an appropriate dye to be used as an indicator because it could reproducibly create tooth staining and the staining could be bleached by hydrogen peroxide. In addition, light irradiation plus the addition of Fe/Sodium-Y or Mn/Sodium-Y could elevate the bleaching efficacy of hydrogen peroxide. Although the staining and bleaching processes of teeth should be as close to the clinical situation as possible, the staining procedure adopted in the present study was similar to previously related reports $[7,11]$, where the researchers immersed the specimens in whole blood or tea to create discoloration. This method could accelerate the staining process. Also inhomogeneous staining could occur if Orange II was used to stain the teeth only through the intact original surface. For the bleaching procedure, the color changes at three sites (enamel, outer dentin, and inner dentin) for each specimen were evaluated by apply- ing bleaching materials directly on sectioned surfaces instead of outer intact enamel surfaces. The reason was that different teeth exhibit different thickness of enamel and dentin. If the bleaching materials were applied on outer intact enamel surfaces, it would greatly increase the variation of bleaching efficiency and standardization would be difficult to achieve. Therefore, the teeth were stained and bleached through the sectioned surfaces. The materials and methods used in this study can serve as a basic model to evaluate different bleaching materials and techniques before extensive clinical trials, or by students to learn tooth bleaching techniques. Nevertheless, a certain amount of precaution should be taken before the results of this in vitro study are extended to clinical applications as the causes of tooth discoloration might be surface precipitation of dietary chromogens [36], decomposition of pulp tissue [7], medicaments, and filling materials [37]. In the future, the efficacy of Fe/Sodium-Y or Mn/Sodium-Y in combination with $\mathrm{H}_{2} \mathrm{O}_{2}$ against other chromogens might require to be further investigated.

\section{REF E R E N C E S}

[1] Watts A, Addy M. Tooth discolouration and staining: a review of the literature. Br Dent J 2001;190:309-16.

[2] Addy M, Moran J. Mechanisms of stain formation on teeth, in particular associated with metal ions and antiseptics. Adv Dent Res 1995;9:450-6.

[3] Heymann HO. Additional conservative esthetic procedures. In: Sturdevant's art \& science of operative dentistry. St. Louis, Missouri, USA: Mosby Inc.; 2002. p. 605-6.

[4] Rosenstiel SF, Gegauff AG, McCafferty RJ, Johnson WM. In vitro tooth color change with repeated bleaching. Quintessence Int 1991;22:7-12.

[5] Haywood VB, Heymann HO. Nightguard vital bleaching. Quintessence Int 1989;20:173-6.

[6] Collins LZ, Maggio B, Liebman J, Blanck M, Lefort S, Waterfield $\mathrm{P}$, et al. Clinical evaluation of a novel whitening gel, containing $6 \%$ hydrogen peroxide and a standard fluoride toothpaste. J Dent 2004;32:13-7.

[7] Freccia WF, Peters DD. A technique for staining extracted teeth: a research and teaching aid for bleaching. J Endodon 1982;8:67-9.

[8] Addy M, Prayitno S, Taylor L, Cadogan S. An in vitro study of the role of dietary factors in the aetiology of tooth staining associated with the use of chlorhexidine. J Periodontol Res 1979;14:403-10.

[9] Pretty IA, Edgar WM, Higham SM. The use of QLF to quantify in vitro whitening in a product testing model. Br Dent J 2001;191:566-9.

[10] Sharif N, MacDonald E, Hughes J, Newcombe RG, Addy M. The clinical stain removal properties of 'whitening' toothpaste products: studies in vitro. Br Dent J 2000;188:620-4.

[11] Sulieman M, Addy M, Rees JS. Development and evaluation of a method in vitro to study the effectiveness of tooth bleaching. J Dent 2003;31:415-22.

[12] Frysh H. Chemistry of bleaching. In: Complete dental bleaching. Quintessence Publishing Co. Inc.; 1995. p. 28.

[13] McCaslin AJ, Haywood VB, Potter BJ, Dickinson GL, Russell $\mathrm{CM}$. Assessing dentin color changes from nightguard vital bleaching. JADA 1999;130:1485-90.

[14] Joiner A. Tooth colour: a review of the literature. J Dent 2004;32:3-12. 
[15] van der Burgt TP, Bosch JJT, Borsboom PCF, Kortsmit WJPM. A comparison of new and conventional methods for quantification of tooth color. J Prosthet Dent 1990;63:15562.

[16] Paul S, Peter A, Pietroban N, Hammerle CHF. Visual and spectrophotometric shade analysis of human teeth. J Dent Res 2002;81:578-82.

[17] O'Brien WJ, Groh CL, Boenke KM. A new, small-color-difference equation for dental shades. J Dent Res 1990;69:1762-4.

[18] Schwabacher WB, Goodkind RJ. Three-dimensional color coordinates of natural teeth compared with three shade guides. J Prosthet Dent 1990;64:425-31.

[19] Tung FF, Goldstein GR, Jang S, Hittelman E. The repeatability of an intraoral dental colorimeter. J Prosthet Dent 2002;88:585-90.

[20] Douglas RD. Precision of in vivo colorimetric assessments of teeth. J Prosthet Dent 1997;77:464-70.

[21] Okubo SR, Kanawati A, Richards MW, Childress S. Evaluation of visual and instrument shade matching. J Prosthet Dent 1998;80:642-8.

[22] Hammad IA, Stein RS. A qualitative study for the bond and color of ceramometals. Part II. J Prosthet Dent 1991;65:169-79.

[23] Goldstein GR, Schmitt GW. Repeatability of a specially designed intraoral colorimeter. J Prosthet Dent 1993;69:616-9.

[24] Gerlach RW, Barker ML, Sagel PA. Objective and subjective whitening response of two self-directed bleaching systems. Am J Dent 2002;15:7A-12A.

[25] Munsell AH. A color notation. Baltimore: Munsell Color Co.; 1981.

[26] Rubiño M, García JA, del Barco LJ, Romero J. Colour measurement of human teeth and evaluation of a colour guide. Color Res Appl 1994;19:19-22.
[27] Hasegawa A, Motonomi A, Ikeda I, Kawaguchi S. Color of natural tooth crown in Japanese people. Color Res Appl 2000;25:43-8.

[28] Shellis RP. Transport processes in enamel and dentine. In: Addy M, Embery G, Edgar WM, Orchardson R, editors. Tooth wear and sensitivity. London: Martin Dunitz; 2000. p. 19-28.

[29] Pashley DH. Clinical correlations of dentin structure and function. J Prosthet Dent 1991;66:777-81.

[30] Kaneko J, Inoue S, Kawakami S, Sano H. Bleaching effect of sodium percarbonate on discolored pulpless teeth in vitro. J Endodon 2000;26:25-8.

[31] Cheng M, Ma W, Li J, Huang Y, Zhao J. Visible-light-assisted degradation of dye pollutants over Fe(III)-loaded resin in the presence of $\mathrm{H}_{2} \mathrm{O}_{2}$ at neutral $\mathrm{pH}$ values. Environ Sci Technol 2004;38:1569-75.

[32] Lopez A, Kiwi J. Modeling the performance of an innovative membrane-based reactor. Abatement of azo dye (Orange II) up to biocompatibility. Ind Eng Chem Res 2001;40:1852-8.

[33] Goldstein S, Meyerstein D. Comments on the mechanism of the "Fenton-like" reaction. Acc Chem Res 1999;32:547-50.

[34] Smith BA, Teel AL, Watts RJ. Identification of the reactive oxygen species responsible for carbon tetrachloride degradation in modified Fenton's systems. Environ Sci Technol 2004;38:5465-9.

[35] Kashima-Tanaka M, Tsujimoto Y, Kawamoto K, Senda N, Ito $\mathrm{K}$, Yamazaki M. Generation of free radicals and/or active oxygen by light or laser irradiation of hydrogen peroxide or sodium hypochlorite. J Endodon 2003;29:141-3.

[36] Addy M, Moran J, Griffiths AA, Wills-Wood NJ. Extrinsic tooth discoloration by metals and chlorhexidine. I. Surface protein denaturation or dietary precipitation? Br Dent J 1985;159:281-5.

[37] van der Burgt TP, Plasschaert AJM. Bleaching of tooth discoloration caused by endodontic sealers. J Endodon 1986;12:231-4. 